\title{
Hypodontia, ankylosis and infraocclusion: report of a case restored with a fibre-reinforced ceromeric bridge
}

\author{
H K Sidhu, ' and A Ali ${ }^{2}$
}

\begin{abstract}
Retained primary molars without permanent successors often undergo progressive infra-occlusion, without predictable exfoliation. Early prophylactic removal, after assessment of root resorption and adjacent periodontal support loss as well as age of onset, is often indicated. This article describes the joint orthodontic-restorative care of such a case and describes an alternative method of restoration using a fibre-reinforced ceromeric bridge. As well as a conservative preparation and good aesthetics, an overlay restoration provided a fully functional occlusion.
\end{abstract}

$\mathrm{H}$ ypodontia is the absence of development of teeth with a higher incidence in the permanent dentition ranging from $3.5-6.5 \%,{ }^{1}$ than in the primary dentition at $0.1-0.9 \% .^{2}$ As well as anomalies of number, teeth may be of abnormal shape, size or colour. Anomalies of position, path and timing of eruption and exfoliation are also seen. Bjerklin ${ }^{3}$ described these different dental anomalies to be expressions of one syndrome, with incomplete penetrance and each with variable expressivity. A higher frequency of ectopic eruption of maxillary canines has been proven in patients with either aplasia of premolars, infra-occlusion of premolars or ectopic eruption of maxillary first permanent molars, compared to the expected population frequency. A specific association of aplasia of premolars was noted in $17 \%$ of cases of infra-occluded deciduous molar teeth. ${ }^{4}$

Ankylosis, a specific anomaly, involves fusion of cementum to alveolar bone and affects almost all infra-occluded deciduous molars. It may, however, develop subsequent to the infra-occlusion, ${ }^{4}$ often at a microscopic level and any obliteration of the periodontal ligament can be undetected on

${ }^{1}$ Senior House Officer ${ }^{2}$ Consultant/Honorary

Clinical Senior Lecturer, Department of Restorative

Dentistry, Glasgow Dental Hospital \& School,

378 Sauchiehall Street, Glasgow G2 3JZ;

${ }^{*}$ Correspondence to: A. Ali

email:arshadali@breathe.com

REFEREED PAPER

Received 02.02.01; Accepted 31.05.01

() British Dental Journal 2001; 191: 613-616 conventional radiographs. The ultimate diagnosis is therefore based on clinical findings of a sharp, clear note on percussion as well as immobility. Ankylosis may occur at any time during eruption and can lead to submergence. After eruption it halts any adjacent occlusal plane vertically. This gives the impression of being submerged. Nonresponse, with no associated pain during orthodontic therapy, is also thought to be indicative of ankylosis. Primary molars have the highest incidence of ankylosis ranging from $1.5-9.9 \% .^{5}$ Various theories as to the aetiology of ankylosis have been suggested. Defects or any discontinuity within the periodontal ligament can predispose to ankylosis, as stated by the traumatic theory. It may be due to injury to bone or periodontal ligament resulting in regenerative processes causing ankylosis. This, however, was dismissed by some after in vivo studies failed to produce ankylosis. ${ }^{6}$ The disturbed local metabolism theory is based on the belief that root resorption in primary teeth precedes disappearance of the periodontal leads to obliteration of the periodontal ligament first and the resulting close contact of the bone to the tooth structure allows union. ${ }^{7}$ However, evidence is also present to suggest a genetic predisposition to ankylosis. This is based on findings that the prevalence of ankylosis amongst siblings is $46 \%$ compared with a control of $1.3 \%$ in American children. ${ }^{8}$ Koyoumdjisky and Steigman also adaptive changes as facial growth carries the ligament. Disruption in local metabolism found a genetic predisposition to submergence in their studies on different ethnic groups living in Israel. ${ }^{9}$ Although the exact mechanism of initiation of ankylosis remains uncertain, changes have been reported in the position and appearance of the cell rests of Mallassez within ankylosed primary molars. This distribution of the cell rests has been thought to be relevant to the subsequent likelihood of development of ankylosis and resorption. ${ }^{10}$

The term 'infra-occlusion' describes the clinical picture without labelling the aetiology. Infra-occlusion predominantly affects the mandibular arch, with the reported incidence varying between $1.3 \%{ }^{8}$ and between 8 and $14 \%$ amongst $6-11$ year olds. ${ }^{11}$ A surprisingly high prevalence has been reported amongst Israeli children at $38.5 \% .^{12}$ Many classifications of infra-occlusion have been described. One simple classification was described by Brearley. ${ }^{13}$

- Slight - occlusal surface located approximately $1 \mathrm{~mm}$ below the expected occlusal plane for the tooth.

- Moderate - occlusal surface approximately level with the contact point of one or both adjacent tooth surfaces.

- Severe - occlusal surfaces level with or below the interproximal gingival tissue of one or both adjacent tooth surfaces.

Severe infra-occlusion only affects $2.5-8.3 \%$ of all infra-occluded deciduous molars ${ }^{4}$ but has been found specifically to be related to lack of a permanent successor. Infra-occlusion of primary molars in cases of aplasia of the permanent premolars should be approached with special precaution. In all cases of infra-occlusion of primary teeth, normal exfoliation is delayed. In patients where the permanent successors are present this is found to be approximately within six months of the expected time. In cases of aplasia this has been found to be significantly longer. A slower increase is seen in the extent of infra-occlusion with age, as well as the rate of root resorption. ${ }^{14}$ However, this 
does still introduce an element of ambiguity to the long-term prognosis. Not only is there increased risk of occlusal disturbances, such as mesial tipping of the first permanent molar, but the marginal alveolar bone falls following the cemento-enamel junction of the infra-occluded tooth as it continues to submerge. In such cases, treatment should be planned early with combined orthodontic and restorative assessment to consider the treatment options. The options for restoration and replacement of teeth have increased over the last $10-15$ years, with the advent of better tooth-coloured materials. The following case describes the management of a case with hypodontia, ankylosis and infra-occlusion.

\section{Case report}

A healthy 11-year-old Asian female was referred to the Orthodontic Department at Glasgow Dental Hospital and School by her general dental practitioner. She complained of prominent upper anterior teeth. Her medical history was unremarkable and she visited her dentist regularly.

On examination she presented with an Angles class 11 division 1 incisor relationship on a class 11 skeletal base. Teeth present were:

UR7, UR6, URE, URD, UR3, UR2, UR1, UL1, UL2, UL3, UL4, ULE, UL6, UL7

$17,16,55,54,13,12,11,21,22,23,24,65$, 26,27

LR7, LR6, LR5, LR4, LR3, LR2, LR1, LL1, LL2, LL3, LL4, LL5, LL6, LL7

$47,46,45,44,43,42,41,31,32,33,34,35$, 36,37

with UR4, UR5, UL5 $(14,15,25)$ developmentally absent. As well as an increased overjet $(8 \mathrm{~mm})$ the overbite was also slightly increased $(5 \mathrm{~mm})$, with slight proclination of the upper lateral incisor teeth. Crowding in rotated teeth were absent in the upper arch and crowding was mild in the lower arch. The URE, URD $(55,54)$ were retained and severely infra-occluded with marked root resorption and ankylosis. Slight mesial tipping of the UR6 (16) was noted. The retained ULE (65) was less severely infraoccluded with only the distal marginal ridge lower than that of the adjacent UL6 (26).
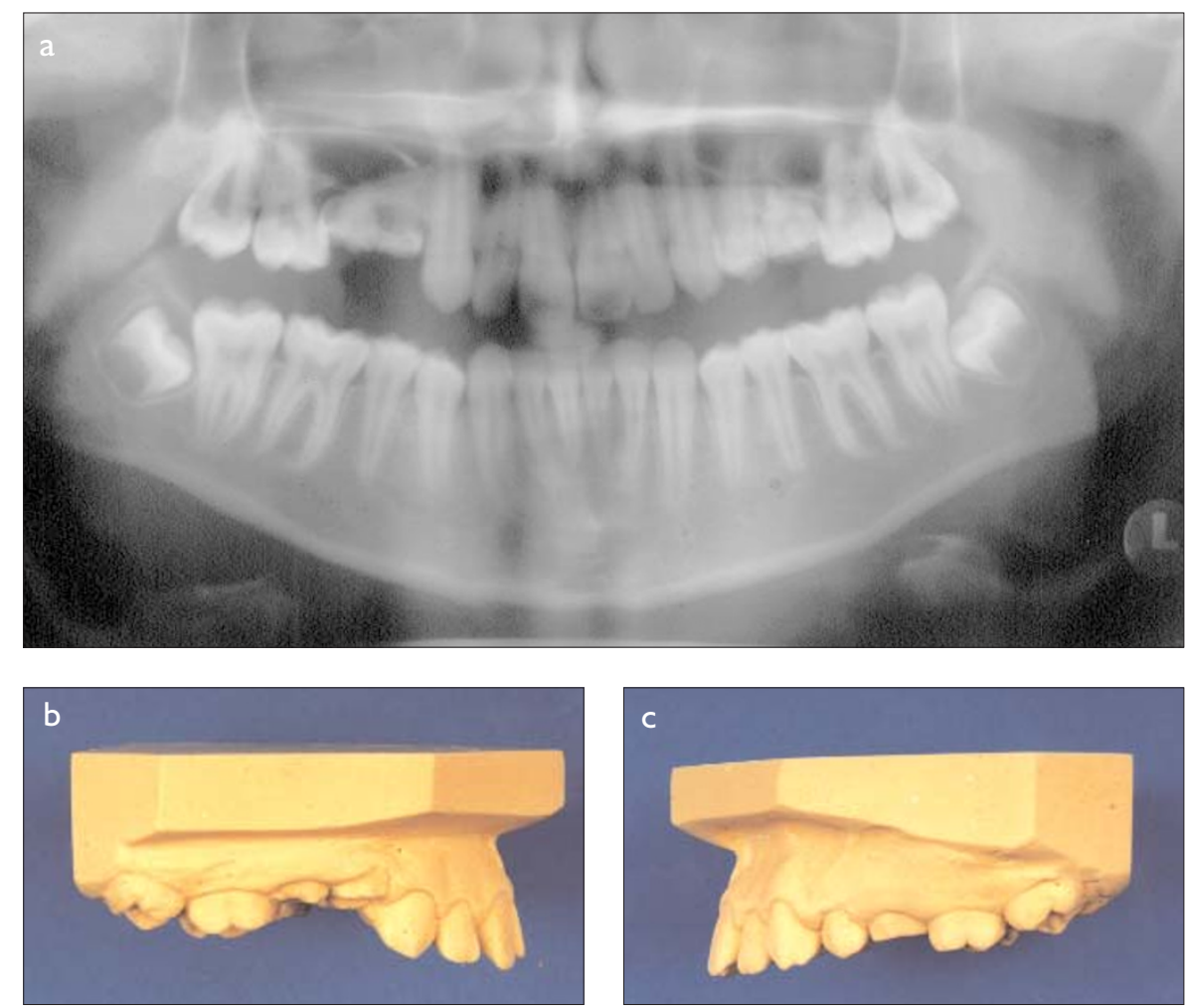

Fig. I. (a) Orthopantomogram showing the retained infra-occluded deciduous molars with missing permanent successors. Note also the extent of the deciduous root resorption. (b) Buccal view of the infra-occluded teeth UR4, UR5 $(54,55)$ highlighting the extent of the vertical discrepancy. (c) Buccal view of the infra-occluded tooth ULE (65).

The roots of ULE (65) were also markedly resorbed (Figs la-c).

The patient was fully assessed clinically and radiographically. Study casts were constructed and analysed. In view of the degree of root resorption of the retained deciduous teeth, the severity of the infra-occlusion and the risk of increasing loss of bony support of the adjacent permanent teeth, it was decided to extract all the retained deciduous molars. Pre-restorative orthodontic treatment was considered with fixed appliance therapy. The aims of orthodontic therapy were as follows.

Closure of the single unit space in the upper left quadrant

Reduction of the two unit space in the upper right quadrant to a single unit with uprighting of the UR6 (16).

\section{Correction of the overbite and overjet}

The above treatment would have required fixed appliance therapy, which was declined by the patient. The limitations of removable appliance therapy were fully explained to the patient and parent and it remained her treatment of choice. Two removable appli- ances were used for the treatment; one to retract UR3, UL3, UL4 $(13,23,24)$ and another to retract UR1, UR2, UL1, UL2 (11, $12,21,22)$. Both also incorporated bite planes to aid in overbite reduction. As a reaction to retraction of UR3 (13), poor bodily control of UR6 (16) resulted in an increase in its mesial inclination.

When pre-restorative orthodontic treatment was near completion the patient was reassessed at a combined orthodonticrestorative clinic to confirm that the size of the space for UR5 (15) was correct. There was some increase in the upper anterior spacing and the patient was happy to accept this (Figs 2a-d).

Impressions were taken for study casts and a diagnostic wax up was carried out to assess the pontic size, shape, position and occlusion.

Options for treatment included:

- Partial denture

- Bridge: fixed - fixed

- Cantilever

- Resin bonded

- Single tooth implant

As there was only one missing unit, a den- 

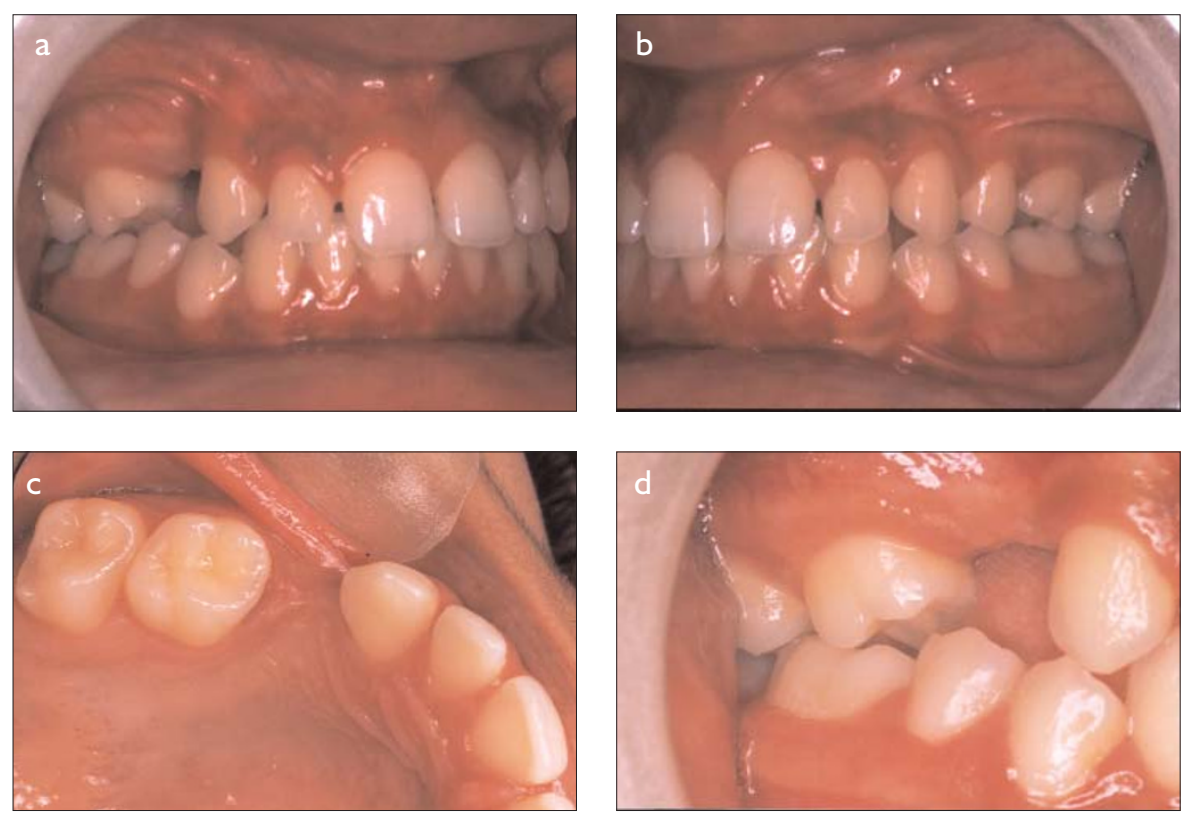

Fig. 2. (a) Post-orthodontic treatment - right side. (b) Post-orthodontic treatment - left side. (c) Occlusal view of the residual edentulous unit in the upper right quadrant after orthodontic therapy. (d) Buccal view showing the mesial tipping of the tooth UR6 (16).

ture was not considered. Implant treatment was found to be compromised by the lack of available bone (Fig. 3). Augmentation of the area was rejected by the patient as a possibility. Conventional bridgework is very destructive of tooth tissue and therefore resin-retained bridgework was considered. This also presented aesthetic difficulties. The mesially tilted UR6 (16) would result in a highly visible metal retainer. Another option was to consider

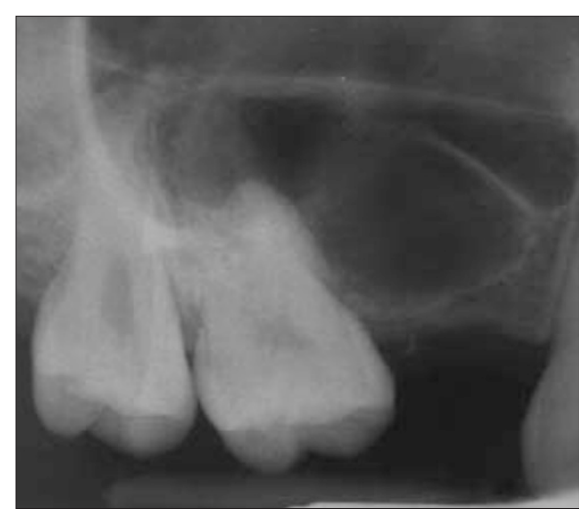

Fig. 3. Periapical radiograph showing the reduced bone level and proximity of the maxillary sinus to the edentulous ridge, making implant insertion impossible without ridge augmentation. the use of a fibre-reinforced ceromeric bridge. This would allow replacement of UR5 (15) and overlaying of UR6 (16) with a tooth-coloured restorative material. The preparation involved production of a chamfer finish line on the palatal and mesial surfaces of UR6 (16), along with minor recontouring of the mesial cusp slopes (Figs 4). A master impression was taken with a polyether material (Permadyne Penta ${ }^{\mathrm{TM}}$ ) and an opposing arch impression taken with an alginate substitute (Position Penta ${ }^{\mathrm{TM}}$ ). The bridge was constructed using fibre reinforcement and an overlying ceromeric material (Connect $^{\mathrm{TM}}$ and Belleglass $\left.{ }^{\mathrm{TM}}\right)$. The restoration was tried in and the fit, shade and occlusion checked. A rubber dam was placed, the preparation was cleaned with pumice and etched. The restoration was bonded using a dual cured composite resin $\left(\right.$ Nexus $\left.^{\mathrm{TM}}\right)$. Excess resin was carefully removed prior to curing. Final excess was removed after curing and the occlusion checked. The patient was very pleased with the aesthetic result and has been followed up for a period of 18 months during which there have been no clinical or technical problems (Figs 5a and b).

\section{Discussion}

Cases of infra-occlusion of primary molars accompanied by aplasia of the permanent premolars should be recognized as unusual cases. Diagnostic considerations include the age of the patient, occlusal status, condition of the infra-occluded tooth including the degree of infra-occlusion and root resorption, as well as adjacent alveolar bone levels. Timing of treatment is dependant on the prognosis of the infraoccluded tooth, judged by the above. There have been reports in the literature of restoration of primary molars without permanent successors. Where adequate periodontal support allows, such teeth have been restored to maintain occlusal balance and adequate cleaning using porcelain crowns ${ }^{16}$ and indirect composite onlays. ${ }^{17}$ Restoration of infra-occluded teeth to the occlusal plane may provide a good immediate result, but progressive infra-occlusion with facial growth and continued root resorption threatens later exfoliation, and this is often not a long-term solution. Predictable treatment can often only be provided by extraction and orthodontic therapy. Generally this is best carried out early allowing some mesial drift of the first permanent molar, limiting the reduction of the adjacent alveolar bone, as well as being during the age of good orthodontic response. This case highlights some of the considerations needed in treatment planning such complex cases and emphasizes the importance of combined specialty clinics to fully understand strengths and limitations of treatments offered to patients. In this case the inferior outcome of removable appliance therapy was recognized as well as aesthetic difficulties of restoration due to

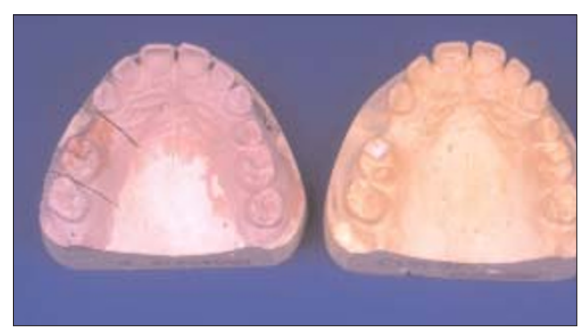

Fig. 4. Occlusal view of the upper arch after orthodontic treatment; note the minimal preparation of UR6 (16). 

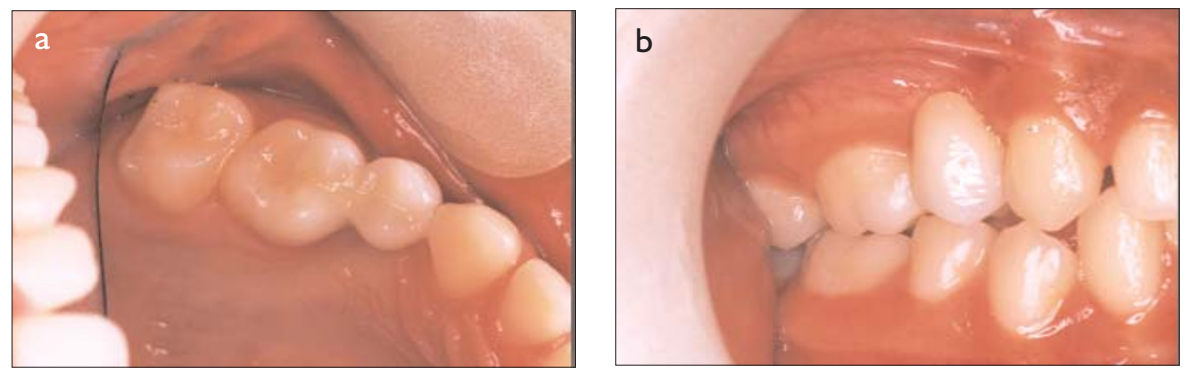

Fig. 5. (a) Occlusal view of the ceramic polymer bridge. (b) Buccal view of the ceramic polymer bridge in intercuspal position. As well as good aesthetics, overlay of the mesial cusps of UR6 (I6) establishes a functional occlusion.

drift of the first permanent molar. The restoration was completed satisfactorily with a new ceramic optimized polymer. These materials have been developed to attempt to overcome some of the problems associated with polymer-based systems, such as wear resistance, maintenance of polish and staining. ${ }^{18}$ Ceromers have been defined as improved composite with increased cross-linking and increased degree of polymerization. ${ }^{19}$ These materials have had their physical properties optimized. The improvements are due to higher filler loading and the incorporation of multi-functional monomers that have more bonding sites resulting in greater cross-linking between the polymeric chains. The material is also cured under heat, pressure and nitrogen, which also improves strength and wear characteristics. Fibre reinforcement also enhances the physical properties. Studies have demonstrated high flexural strengths of up to 900 $\mathrm{MPa}$, which is very much higher than metal ceramic restorations ${ }^{20,21}$. The fibres are translucent and can be easily shade matched to the natural dentition. With regard to inlays, onlays and veneers, clinical studies do show a high success rate over a five-year period ${ }^{22}$. There are problems with regard to marginal staining, which is likely to be due to loss of integrity of the luting resin. There are, however, no longterm studies with regard to ceromeric crowns or bridgework. Patients should be made aware of this and cases should be carefully monitored over the long term.

The authors would like to thank Mr. P Benington, Consultant Orthodontist for his advice and the Department of Dental Illustration at Glasgow Dental Hospital \& School.

1 Brook A H. Dental anomalies of number, form and size: their prevalence in British schoolchildren. J Int Assoc Dent Child 1974; 5: 37-53.

2 Welbury R R. Paediatric Dentistry. pp 257. Oxford University Press, 1997.

3 Bjerklin K, Kurol J, Valentin J. Ectopic eruption of maxillary first permanent molars and association with other tooth and developmental disturbances. Europ J Ortho 1992; 14: 369-375. infra-occlusion and failed eruption of deciduous molars associated with eruptive and developmental disturbances in the permanent dentition: a report of 28 selected cases. $\mathrm{Br} \mathrm{J}$ Ortho 1997; 24: 149-157.

5 Albers D A. Ankylosis of teeth in the 17: 303-308.
4 Winter G B, Gelbier M J, Goodman J R. Severe developing dentition. Quintessence Int 1986;
6 Robin P L, Biederman W. Attempt to produce tooth ankylosis. J Dent Res 961; 40: 744.

7 Biederman W. The problem of the ankylosed tooth. Dent Clin N Am 1968; Jul: 409-424.

8 Via N F. Submerged deciduous molars: Familial tendencies. J Am Dent Assoc 1964; 69: 127-129.

9 Koyoumdjisky-Kaye E, Steigman S. Ethnic variability in the prevalence of submerged primary molars. J Dent Res 1982; 6: 1401-1404.

10 Rygh P, Reitan K. Changes in the supporting tissues of submerged deciduous molars with and without permanent successors. Eur Orthod Soc $\operatorname{Tr} 1963$; 39: 171-184.

11 Kurol J. Infraocclusion of primary molars: an epidemiologic and familial study. Community Dent Oral Epidemiol 1981; 9: 94-102.

12 Steigman S, Koyoumidjisky-Kaye E, Matrai Y. Submerged deciduous molars in the preschool children: an epidemiologic survey. J Dent Res 1973; 52: 322-326.

13 Brearley L J, Mc Kibben D H. Ankylosis of primary molar teeth 1 . Prevalence and characteristics. J Dent Child 1973; 40: 54-63.

14 Kurol J, Tilander B. Infra-occlusion of primary molars with aplasia of the permanent successor. A longitudinal study. Angle Orthod 1984; 54: 283-294.

15 Radz G M. An improved composite-onlay system. Compendium 1997; 18: 98-104.

16 Gulati A K, Welbury R R. The use of resinbonded porcelain crowns for primary molars in infra-occlusion. Br Dent J 1998; 184: 588-591.

17 Evans R D, Briggs P F A. Restoration of an infra-occluded primary molar with an indirect composite onlay: a case report and literature review. Dent Update 1996; 23: 52-54.

18 Vallittu P K. Prosthodontic treatment with a glass fiber-reinforced resin-bonded fixed partial denture: A clinical report. J Prosthet Dent 1999; 82: 132-135.

19 Ceromeric Crowns and Fixed Partial Dentures: CRA Newsletter. 1997; 21(5).

20 Leinfelder K F et al. New Developments in Resin Restorative Systems. J Am Dent Assoc 1997; 128 (5): 573-581.

21 Miara P. Aesthetic Guidelines for Second Generation Indirect Inlay and Onlay Composite Restorations. Pract Periodont Aesthet Dent 1998; 10 (4): 423-431.

22 O'Neal et al. Five Year Clinical Performance of Heat and Pressure Cured Indirect Composite. IADR 1999; abs 1628. 